Научная статья

УДК 658.3.07

DOI 10.18101/2304-4446-2021-3-74-80

\title{
ОСОБЕННОСТИ РЕАЛИЗАЦИИ КАДРОВОЙ ПОЛИТИКИ В УПРАВЛЕНИИ ЧЕЛОВЕЧЕСКИМИ РЕСУРСАМИ
}

\section{(C) Садыхов Рахим Фарахим оглы}

доктор философии по экономике, доцент, Бакинский университет бизнеса

Азербайджан, AZ1122, Баку, ул. Г. Зардаби, 88а

s.rahim72@mail.ru

\begin{abstract}
Аннотация. Целью исследования является изучение планирования работы персонала на промышленных предприятиях, их мотивации в трудовой деятельности, карьерного роста и других вопросов. Трудовые ресурсы представляются обществу как активные социальные ресурсы, которые играют особую роль в производстве товаров и услуг. Это означает, что существует постоянная потребность в изучении человеческих ресурсов на предприятии. С этой целью мы стремимся проводить исследования в области управления человеческими ресурсами на предприятии.

Методология исследования - это систематическое, процедурное и всестороннее изучение организации и управления человеческими ресурсами. Управление человеческими ресурсами на предприятиях - одна из основных подсистем общей стратегии фирмы.

Результат исследования - совершенствование стратегического управления человеческими ресурсами, которое состоит из концептуальных нововведений в этой области. Применение результатов исследования в деятельности промышленных предприятий послужит повышению кадрового потенциала, развитию и стимулированию трудовой активности этих предприятий.

Ключевые слова: предприятие, менеджмент, стратегия, человеческие ресурсы, кадровая политика, концепция, персонал, мотивация, экономические стимулы, карьера, трудовая деятельность
\end{abstract}

\section{Для цитирования}

Садыхов Р. Ф. Особенности реализации кадровой политики в управлении человеческими ресурсами // Вестник Бурятского государственного университета. Экономика и менеджмент. 2021. № 3. С. 74-80.

Организация и успешное внедрение менеджмента на предприятии - один из основных стратегических вопросов. Успешная реализация процессов на предприятии зависит от содержания поставленных стратегических целей и их достижения на необходимом уровне. Управление - это система социальной активности, которая возникает в результате целенаправленного воздействия управляющих и управляемых субъектов друг на друга. Менеджмент - продукт человеческого мышления в сфере социальной деятельности.

Человеческое мышление - продукт человеческой психологии. Следовательно, источником управления человеческими ресурсами является психология человека, объектом ее воздействия являются человеческие ресурсы [16]. Психология управления, ориентируясь на рабочую силу в трудовой деятельности, формирует 
$P . \Phi$. Садbххов. Особенности реализации кадровой политики в управлении человеческими ресурсами

основу для их морального стимулирования, мотивации и успешного выполнения своих обязанностей. Для этого считаем целесообразным провести исследования в этой области. Основная цель здесь — правильно спланировать человеческие ресурсы на уровне предприятия, добиться их социального развития, мотивировать их в управлении и так далее.

Применение управления человеческими ресурсами с корпоративной точки зрения является ключевым компонентом стратегического управления предприятием. Человеческие ресурсы являются основным и наиболее важным ресурсом для планирования, организации, реализации и контроля деятельности на предприятии [1]. Роль кадрового планирования, кадрового обеспечения и социального развития сотрудников в эффективной организации стратегического управления на промышленных предприятиях высока. Стратегическое управление человеческими ресурсами заключается в активизации действий, влияющих на субъектов и их психологию, управление деятельностью которых осуществляется с помощью различных методов управления.

Психология управления фокусируется на нацеливании менеджеров на рабочую силу в процессе труда, поскольку социальная сущность является основой их моральной мотивации и успешной работы. Успешное управление - один из ключевых вопросов стратегического управления [21]. Ведь успешная реализация процесса позволяет достичь поставленных стратегических целей на необходимом уровне. С этой точки зрения лидер должен не только регулировать деятельность, действия, поведение и отношения своих подчиненных, но также правильно планировать свою деятельность и поведение и регулировать свои управленческие отношения с другими [5].

Рассмотренное с этой точки зрения подразделение позволяет определить потребность в кадрах соответствующей специализации, профессиональных навыков и опыта с точки зрения выполнения соответствующих функций. Однако такое требование систематизируется или классифицируется в соответствующих штатных единицах на основе организационных и финансовых возможностей организации. Выполнение функций также должно соответствовать специфике применения методов.

В следующей таблице показаны результаты и эффективность методов управления при реализации любых функций управления в течение стратегического периода, а также представлена матрица качества взаимодействия функций и методов управления (табл. 1). Однако в этой матрице классифицируются только три функции управления. Только к функциям, упомянутым в матрице, можно подходить со стратегической точки зрения. Однако, поскольку организационные и исполнительные функции являются текущими, они не могут быть индикаторами анализа результатов матрицы качества за стратегический период.

Таблица представляет собой дорожную карту, которая направляет, реализует и характеризует результаты управления путем применения соответствующих функций и методов к организации. Применяя матрицу, менеджеры имеют возможность прогнозировать последствия применения экономических, административных и социально-психологических методов в управлении на этапах планирования, маркетинга и контроля. 
Таблица 1

Матрица качества совместного и взаимосвязанного применения функций и методов управления

\begin{tabular}{|c|c|c|c|}
\hline & Планирование & Маркетинг & Контроль \\
\hline $\begin{array}{l}\text { Экономический } \\
\text { метод }\end{array}$ & $\begin{array}{l}\text { Планирование продук- } \\
\text { та. } \\
\text { Планирование доходов } \\
\text { от продаж. } \\
\text { Планирование эконо- } \\
\text { мической эффективно- } \\
\text { сти }\end{array}$ & $\begin{array}{l}\text { Исследования } \\
\text { рынка. } \\
\text { Ценообразование. } \\
\text { Выручка от про- } \\
\text { даж }\end{array}$ & $\begin{array}{l}\text { Вознаграждения, } \\
\text { санкции, } \\
\text { штрафы }\end{array}$ \\
\hline $\begin{array}{l}\text { Административный } \\
\text { метод }\end{array}$ & $\begin{array}{l}\text { Формирование норма- } \\
\text { тивно-правовой базы. } \\
\text { Формирование органи- } \\
\text { зационной структуры, } \\
\text { Определение механиз- } \\
\text { ма управления }\end{array}$ & $\begin{array}{l}\text { Регулирование } \\
\text { торговых отноше- } \\
\text { ний }\end{array}$ & $\begin{array}{l}\text { Механизмы управ- } \\
\text { ления. } \\
\text { Административные } \\
\text { меры. } \\
\text { Дисциплинарные } \\
\text { меры }\end{array}$ \\
\hline $\begin{array}{l}\text { Социально- } \\
\text { психологический } \\
\text { метод }\end{array}$ & $\begin{array}{l}\text { Определение социаль- } \\
\text { ных потребностей со- } \\
\text { трудников. } \\
\text { Планирование обще- } \\
\text { ственных мероприятий }\end{array}$ & $\begin{array}{l}\text { Удовлетворение } \\
\text { рыночного спроса. } \\
\text { Обеспечение удо- } \\
\text { влетворенности } \\
\text { клиентов }\end{array}$ & $\begin{array}{l}\text { Регулирование } \\
\text { общественных от- } \\
\text { ношений }\end{array}$ \\
\hline
\end{tabular}

Источник: Разработано автором

Матрица качества управления характеризует результаты применения любой функции соответствующими методами. Это описание является руководством к успешной реализации управленческой функции менеджеров, чтобы сделать управление более продуктивным.

Эти функции требуют обеспечения кадрового планирования на начальном этапе процесса управления человеческими ресурсами. Кадровое планирование неотъемлемая часть кадровой политики каждого предприятия. Кадровая политика - это комплекс мероприятий, направленных на привлечение сотрудников, их продуктивное размещение и социальное развитие.

Кадровая политика - часть общей стратегии предприятия. Эта стратегия как долгосрочная программа организации отражает не только расширение материальных ресурсов организации, но и расширение финансовых ресурсов, достижение прибыли и экономической эффективности.

Кадровая политика также является важным условием трансформации человеческих ресурсов в более производительный капитал, который является главным духовным источником формирования и развития этих материальных и экономических составляющих [19].

Кадровая политика - основная концепция формирования, управления и развития человеческих ресурсов на предприятии. Кадровая политика играет важную роль в развитии инициативы, новаторства, способностей и навыков сотрудников.

Кадровую политику определяет руководитель предприятия. Его реализация осуществляется отделом кадров и другими структурными подразделениями. 
$P . \Phi$. Садbххов. Особенности реализации кадровой политики в управлении человеческими ресурсами

В связи с реализацией кадровой политики в ООО «ЭМБАВУД» предусматривается реализация следующих мероприятий:

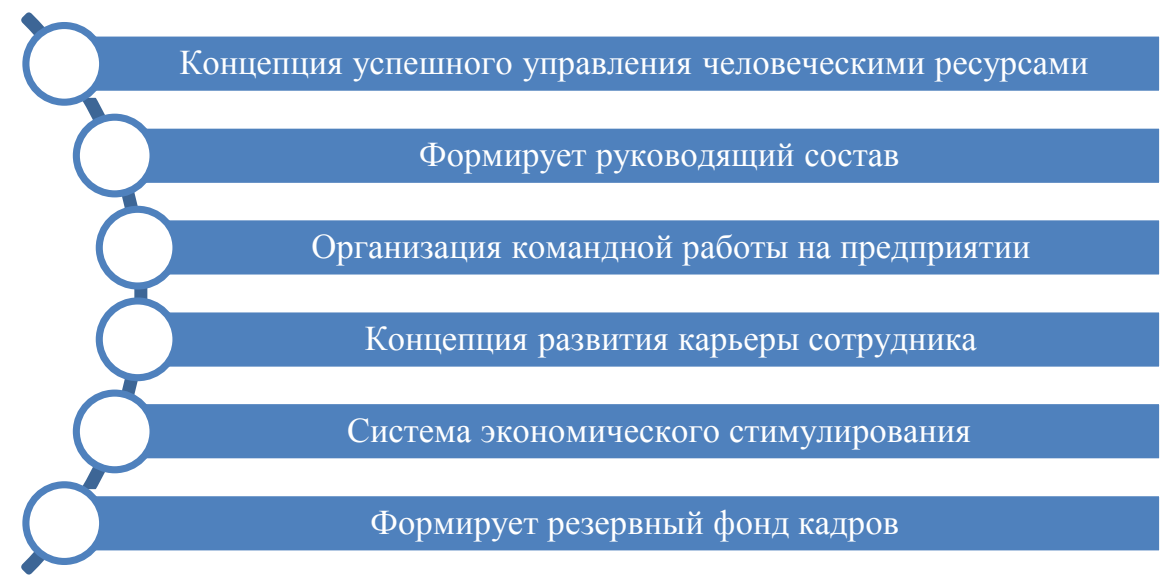

Источник: Разработано автором

Рис. 1. Содержание кадровой политики

Стратегические аспекты управления человеческими ресурсами в организации начинаются с разработки правильной и успешной концепции управления. Мы разработали эту концепцию для ООО «ЭМБАВУД». В данной концепции мы представили механизм формирования управленческого персонала, механизм карьерного роста сотрудников, систему экономических стимулов для стимулирования трудовой активности и резервный фонд.

Следующие тренинги по формированию и обучению менеджеров заслуживают похвалы.

- Развитие карьеры,

- Лидерство и менеджмент,

- Инструменты управления,

- Управление качеством

- Принятие стратегических решений,

- Эффективное управление инициативами.

Развитие финансово-хозяйственной деятельности в современном менеджменте связано с правильной организацией совместной работы в организации и формированием благоприятной рабочей среды. Совместная деятельность руководителей и персонала в трудовом коллективе увеличивает трудовую активность каждого работника [13]. Математико-экономическая модель такого роста активности представлена следующим образом. Ниже приводится математическая формула деятельности персонала, работающего на предприятии:

$$
\mathrm{F}(\mathrm{m})>\mathrm{F}\left(\mathrm{x}_{1}\right)+\mathrm{F}\left(\mathrm{x}_{2}\right)+\ldots+\mathrm{F}\left(\mathrm{x}_{\mathrm{n}}\right)
$$

Обозначим сумму активности персонала, работающего на предприятии, через F (m). Мы отметили активность сотрудников в разных отделах с помощью $\mathrm{F}(\mathrm{X} 1), \mathrm{F}(\mathrm{X} 2), \mathrm{F}(\mathrm{X} 3)$. Тогда формулы активности сотрудников в разных сетях будут такими.

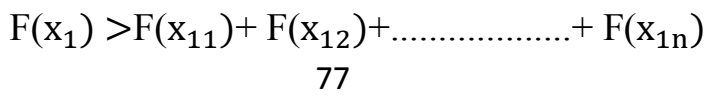




$$
\begin{aligned}
& \mathrm{F}\left(\mathrm{x}_{2}\right)>\mathrm{F}\left(\mathrm{x}_{21}\right)+\mathrm{F}\left(\mathrm{x}_{22}\right)+\ldots \ldots \ldots \ldots \ldots . . .+\mathrm{F}\left(\mathrm{x}_{2 \mathrm{n}}\right) \\
& \mathrm{F}\left(\mathrm{x}_{\mathrm{n}}\right)>\mathrm{F}\left(\mathrm{x}_{\mathrm{n} 1}\right)+\mathrm{F}\left(\mathrm{x}_{\mathrm{n} 2}\right)+\ldots \ldots \ldots \ldots \ldots \ldots+\mathrm{F}\left(\mathrm{x}_{\mathrm{nn}}\right)
\end{aligned}
$$

Таким образом, суммарная активность социальных групп, работающих на предприятии, будет следующей:

$$
\begin{gathered}
\mathrm{F}(\mathrm{m})>\mathrm{F}\left(\mathrm{x}_{11}+\mathrm{x}_{21}+\cdots \mathrm{x}_{\mathrm{n} 1}\right)+\mathrm{F}\left(\mathrm{x}_{21}+\mathrm{x}_{21}+\mathrm{x}_{\mathrm{n} 1}\right)+\ldots \\
+\mathrm{F}\left(\mathrm{x}_{1 \mathrm{n}}+\mathrm{x}_{2 \mathrm{n}}+\cdots+\mathrm{x}_{\mathrm{nn}}\right)
\end{gathered}
$$

Здесь $\mathrm{F}\left(\mathrm{x}_{11}+\mathrm{x}_{21}+\cdots \mathrm{x}_{\mathrm{n} 1}\right)$ - это лицо, работающее на соответствующей должности или звании в каждом отделе (например, руководители отдельных отделов, помощники, старшие специалисты, специалисты и т. д.)

В их деятельности есть случаи совместного сотрудничества. В этом случае объем работы, выполняемой группой, превышает сумму действий сотрудников, работающих по индивидуальным профилям.

Карьерный рост связан с социально-интеллектуальным развитием работника по профессии и условиям труда, продвижением по службе на занимаемой должности. Эта концепция ведет к развитию профессиональных навыков сотрудников, обеспечивает их социальное развитие. Концепция применяется в компании сначала как единая система качественного человеческого капитала, а затем для обеспечения карьерного роста сотрудников.

В концепции, которую мы представили компании, мы считали необходимым реализовать следующие меры для карьерного роста сотрудников:

- Привлечение персонала к профессиональному обучению.

- Привлечение их к международному обмену опытом.

- Улучшение условий труда сотрудников.

- Содействие в их ответственном подходе к своей работе.

По мере того как сотрудники прогрессируют в своей карьере, они становятся более склонны предпринимать исследования, применять инновации, проявлять инициативу и работать в команде.

Система экономического стимулирования является основой социальноэкономической концепции компании [15]. Когда мы разработали систему экономического стимулирования, которую предоставили ООО «ЭМБАВУД», мы адаптировали эту систему к финансовой политике компании. Одна из самых важных вещей, которые любая организация может сделать для стимулирования человеческих ресурсов, - это создать фонд стимулирования. Система экономического стимулирования, которую мы предоставляем компании, включает следующее.

- Система вознаграждения за результативность.

- Система поощрений за творческую и предпринимательскую деятельность сотрудников.

- Система социального развития сотрудников

- Система финансирования участия сотрудников в программах международного обмена опытом.

Не следует полагать, что сотрудники, которые сегодня развивают свою карьеру в нашей организации и движутся к успешному будущему, всегда будут работать с нами и направлять свои усилия на развитие нашей компании. Каждый человек является независимой личностью в соответствии с законодательной системой в сфере трудовой деятельности, выбора работы, карьерного роста. Для 
P. Ф. Садblхов. Особенности реализации кадровой политики в управлении человеческими ресурсами

этого важно иметь резервный состав на замену уходящим из рядов сотрудников в будущем. С этой целью следует принять следующие меры:

- Создать электронный каталог соискателей.

- Поддерживать прямую связь с региональными бюро по трудоустройству.

- Поддерживать прямую связь с университетами, которые проводят соответствующую подготовку.

- Создать базу стажировок в университетах.

- Составить список сотрудников резерва и выбирать различные формы общения с ними.

- Создать базу резервных кадров в организации.

Заключение. Завершая исследование, мы приходим к следующему выводу и резюмируем свое мнение следующим образом:

- Успешное внедрение стратегического управления человеческими ресурсами зависит от формирования успешного аппарата управления.

- Эффективность управления зависит от его успешной реализации с организационной точки зрения.

- Кадровая политика — явный фактор, влияющий на развитие карьеры персонала.

- В основе стимулирования трудовых ресурсов лежит социальноэкономическая концепция.

- Программа стратегического управления включает все аспекты развития предприятия.

Стратегическое управление человеческими ресурсами возникает под влиянием управленческих отношений между его субъектами и структурами, развивается, приобретает новую форму и содержание. Другими словами, источником эффективности и результативности стратегического управления в основном является формирование и развитие отношений между субъектами и объектами выражения, их целенаправленное воздействие друг на друга.

Лumepamypa

1. Abbasov İ. M., Sadiqov R. F. Menecment dərs vəsaiti, 2013.

2. Armstrong M. A Handbook of Human Resource Management. 2006. 957 p.

3. Effective Strategic Planning. The Enterprise Foundation. 2009.

4. İmranov A. İ., Mustafayev A. M. Menecmentdə motivləşdirmə. B., 2004.

5. Məmmədov S. və b. İdarəetmənin əsasları. B., 2009.

6. Ritson Neil. Strategic management. Ventus Publishing ApS. 2011.

7. Robert E. Mitchell. How To Link Democratic Governance With Economic Growth. World Bank. 2008.

8. Səmədzadə Ş. Ә. İstehsal menecmenti. B., 2006.

9. Strategic management framework. Corporate Sevices Administration. 2015.

10. Strategic management in the public sector. Public administration and governance network. 2017.

11. Strategic Plan for Data and Information Management. UNESCO. 2017.

12. Şahbazov K.A. və b. "Menecment” B., 2005.

13. Авдеев В. В. Управление персоналом. Оптимизация командной работы. 2006. $960 \mathrm{c}$.

14. Скотт А. Стратегическое планирование. Эдинбург, 2017.

15. Бухалков М. И. Управление персоналом. Москва: ИНФРА-М, 2005. 368 с. 
16. Дудин М. Н., Лясников Н. В. Управление человеческими ресурсами. Москва: Элит, 2016. 320 с.

17. Ефремова С. М. Особенности стратегии модернизации промышленного производства // Науковедение. 2013. № 4. С. 1-7.

18. Кабушкин Н. И. Основы менеджмента. Москва, 1999. 336 с.

19. Климов Е. А. Управление кадрами организаций. 2005. 184 с.

20. Наумов В. М. Организация предпринимательства. Санкт-Петербург: Питер, 2010. $384 \mathrm{c}$.

21. Семенов А. К. Психология и этика менеджмента в бизнесе. 2004.

22. Фалмер Р. М. Современное управление кадрами предприятий и организаций. 2005. $457 \mathrm{c}$.

Статья поступила в редакциюю 30.06.2021; одобрена после рецензирования 30.07.2021; принята к публикацчии 18.08.2021.

\section{FEATURES OF PERSONNEL POLICY IMPLEMENTATION İN HUMAN RESOURCE MANAGEMENT}

Sadykhov Rakhim Farakhim ogly

$\mathrm{PhD}$ in Economics, A/Prof.,

Baku Business University

88a G. Zardabi St., Baku AZ1122, Azerbaijan

s.rahim72@mail.ru

Abstract. The article studies the work planning of the personnel at industrial enterprises, their performance motivation, career development and other issues. Labour resources are considered by society as active social resources that play a special role in the production of goods and services. This means that there is a constant need for the study of human resources at enterprises. To this end, we strive to conduct research in the field of human resource management at enterprises.

Research methodology is a systematic, procedural and comprehensive study of the organization and management of human resources. Human resource management at enterprises is one of the main subsystems of the company's strategy.

The result of the study is the improvement of strategic human resource management, and the conceptual innovations in this area. The application of the research results in the activities of industrial enterprises will serve to increase the workforce capacity, develop and stimulate the labour activity at these enterprises.

Keywords: enterprise, management, strategy, human resources, personnel policy, concept, personnel, motivation, economic incentive, career, labour activity.

\section{For citation}

Sadykhov Rakhim Farakhim ogly. Features of Personnel Policy Implementation in Human Resource Management. Bulletin of Buryat State University. Economy and Management. 2021; 3: 74-80 (In Russ.).

The article was submitted 30.06.2021; approved after reviewing 30.07.2021; accepted for publication 18.08.2021. 